\title{
CONTENÇÃO DE RISCOS NO BRASIL: UMA QUESTÃO DE ENSINO?
}

\author{
Amanda Castelão Sousa', Rafael Riani de Mendonça² e Valéria da Silva Trajano ${ }^{3}$ \\ Laboratório de Inovações em Terapia, Ensino e Bioprodutos Instituto Oswaldo Cruz / Fiocruz, Brasil. \\ 1'amanda.sousa@ioc.fiocruz.br; ${ }^{2}$ rafael.riani@ioc.fiocruz.br; ${ }^{3}$ valeria.trajano@ioc.fiocruz.br
}

\begin{abstract}
Resumo. O ensino em Biossegurança ainda se encontra em estágio incipiente no Brasil e pouco se conhece sobre essas práticas na área de saúde nos diferentes níveis de ensino. Entretanto, os profissionais de saúde e estudantes da área convivem com riscos constantes provenientes de materiais biológicos de suas atividades. Neste estudo objetivamos compreender como o ensino de Biossegurança se desenvolve no território brasileiro. Para tanto, desenvolvemos uma abordagem qualitativa baseada em uma revisão integrativa no intuito de responder a questão: Como o ensino de contenção de riscos (biossegurança) é abordado nos diferentes níveis de ensino dessa área no Brasil? Nossos resultados demonstraram que o ensino em Biossegurança e as publicações estão centrados na região sudeste, por ser uma região de maior concentração de universidades e instituições de pesquisa. Há falhas no ensino de Biossegurança referente à vacinação, EPI, riscos ocupacionais e precaução universal, com relatos de acidentes de trabalho. O ensino está fragmentado, compartimentalizado e as metodologias empregadas são tradicionais. A nosso ver, um ensino baseado em metodologias ativas, cujos estudantes são protagonistas na construção de conhecimentos sobre Biossegurança, pode ser um dos caminhos para um processo ensino e aprendizagem mais efetivos e significativos para estudantes e profissionais.
\end{abstract}

Palavras-chave: Biossegurança; Contenção de Riscos; Ensino em Biossegurança

\section{RISK CONTAINMENT IN BRAZIL: A TEACHING ISSUE?}

\begin{abstract}
Biosafety education is still at an incipient stage in Brazil and little is known about these health practices at different levels of education. However, health professionals and students in the area live with constant risks from biological materials in their activities. In this study we aim to understand how the teaching of Biosafety develops in the Brazilian territory. To this end, we developed a qualitative approach based on an integrative review in order to answer the question: How is the teaching of risk containment (biosafety) addressed at different levels of education in this area in Brazil? Our results showed that teaching in Biosafety, as well as publications, are centered in the southeast region, as it is a region with the highest concentration of universities and research institutions. There are flaws in the teaching of Biosafety regarding vaccination, PPE, occupational risks and universal precaution, with reports of accidents at work. Teaching is fragmented, compartmentalized and the methodologies employed are traditional. In our view, teaching based on active methodologies, whose students are protagonists in building knowledge about Biosafety, can be one of the paths to a more effective and meaningful teaching and learning process for students and professionals.
\end{abstract}

Keywords: Biosafety; Risk Containment; Biosafety Education

\section{INTRODUÇÃO}

O trabalho do profissional da área de saúde é indispensável à vida apesar de apresentar inúmeros riscos que ameaçam tanto o paciente como o profissional. A fim de minimizar esses riscos foi desenvolvido um campo de conhecimento designado Biossegurança/contenção de riscos. O termo biossegurança pode ser definido como conjunto de práticas, ações e medidas administrativas, técnicas, médicas, psicológicas e educacionais que se relacionam à prevenção de acidentes em ambientes ocupacionais ( $\mathrm{Da}$ 
Costa, 1996). As normas de segurança foram criadas depois da Conferência de Asilomar, pelo National Institute of Health (NIH), nos EUA. A partir de então, a comunidade científica de todo o mundo foi alertada sobre a necessidade de procedimentos de segurança mais efetivos (Penna, 2010).

No Brasil, a Biossegurança só foi estabelecida como área especifica após diversos relatos de graves acidentes e infecções ocorridos em laboratórios nas décadas de 1970 e 1980 (Shatzmayr, 2001). Apenas em 1995 foi criada a Comissão Técnica Nacional de Biossegurança (CTNBio) com o objetivo de estabelecer normas de regulação desde o cultivo até o consumo e descarte de organismos geneticamente modificados (OGM) em território nacional (Scholze, 1999). No entanto, as publicações sobre Biossegurança/Contenção de riscos ainda são escassas no território brasileiro. Como o ensino de contenção de riscos (biossegurança) é abordado nos diferentes níveis de ensino nessa área, no Brasil? Essa é uma das nossas inquietações a qual, objetivamos compreender ao longo deste estudo.

\section{METODOLOGIA}

Esta pesquisa apresenta um caráter exploratório, de abordagem qualitativa, cujo objetivo é realizar um levantamento bibliográfico a fim de avaliar o ensino de Biossegurança desde o ensino técnico até a graduação. Para Minayo (2002, p. 21-22), a "pesquisa qualitativa trabalha com um universo profundo de relações, processos e fenômenos que não podem ser reduzidos a quantificação de variáveis, respondendo a questões muito particulares". Com base nessa definição nos propomos a desenvolver este estudo que compreende uma revisão integrativa sobre os diferentes níveis de ensino de contenção de riscos (biossegurança) no Brasil. $O$ nosso objetivo foi compreender como o ensino de Biossegurança se desenvolve no território brasileiro.

A revisão integrativa se diferencia tanto da revisão sistemática quanto da meta-análise, pois a revisão sistemática consiste de uma síntese das pesquisas relacionadas a um dado específico, com enfoque em estudos experimentais, ensaios clínicos. Além disso, segue um método rigoroso de busca e seleção de pesquisas, avalia a relevância e validade dos achados, assim como coleta, síntese, e interpretação dos dados provenientes das pesquisas. A meta-análise combina evidências de estudos primários por meio de técnicas estatísticas com a finalidade de objetivar e validar os achados e os dados a serem analisados que são armazenados em banco de dados. Já na revisão integrativa, podemos 
analisar conhecimentos específicos produzidos em determinadas áreas num dado período de tempo, tendo em vista a crescente quantidade de informações que são produzidas, principalmente na área da educação. A revisão integrativa nos possibilita a análise de publicações com diferentes metodologias, síntese de determinado conhecimento, identificação de lacunas no assunto que podem ser estudadas, bem como 0 aprofundamento de conhecimento específico e a incorporação e aplicabilidade desses resultados (Souza, Silva, \& Carvalho, 2010).

A revisão integrativa compreende as seguintes etapas: (i) delimitação de um tema, (ii) determinação de parâmetros de busca na literatura, (iii) caracterização dos artigos encontrados no processo de revisão, (iv) análise crítica dos estudos selecionados, (v) análise e interpretação dos resultados, (vi) elaboração da revisão (Mendes, Silveira, \& Galvão, 2008).

A delimitação do tema se refere à pergunta norteadora da pesquisa que determina os estudos que serão incluídos, os meios de identificação que serão adotados, as informações relevantes para a coleta e os resultados a serem mensurados. Em cumprimento a essa etapa delimitamos o tema por meio de nossa pergunta norteadora da pesquisa: Como o ensino de contenção de riscos (biossegurança) é abordado nos diferentes níveis de ensino nessa área no Brasil?

A determinação dos parâmetros de busca na literatura da área precisa garantir uma representatividade da amostra, cujos resultados sejam confiáveis e fidedignos. Para atender esse critério, as buscas para a identificação das publicações desta pesquisa foram realizadas em duas Bibliotecas virtuais de publicações indexadas - Biblioteca Virtual em Saúde (BVS), que nos permite acessa bases de dados como MEDLINE, LILACS e Scielo; Scientific Electronic Library Online (SciELO) e na Base de Dados de Publicações Médicas (PubMed), a qual se mostra mais eficiente nas buscas de artigos indexados na MEDLINE do que a BVS.

Os descritores utilizados para a realização dessas buscas foram os seguintes: 'contenção de riscos' e 'educação'. Esses descritores foram obtidos na consulta ao endereço eletrônico: http://decs.bvs.br/, com os termos em português e inglês. O descritor indicado para a palavra-chave 'biossegurança' é 'contenção de riscos' e para a palavra-chave 'ensino' não havia descritor, então utilizamos o descritor 'educação'. 
Diferente das palavras-chaves, os descritores representam o conceito que se extrai de vocábulo, que descreve o seu conteúdo. Eles são organizados em estruturas hierárquicas e são utilizados pelas bases de dados para indexar os artigos com o intuito de facilitar a pesquisa e, consequentemente, a recuperação do artigo nas bases de dados. Os descritores podem ser formados por uma ou mais de uma palavra (Pompei, 2010; Brandau, Monteiro, \& Braile, 2005).

A fim de verificar se havia variação quantitativa na amostragem e com a finalidade de captar o maior número de publicações sobre o assunto, utilizamos os termos com diferentes combinações, "contenção de riscos e ensino"; "biossegurança e ensino" "contenção de risco e educação" e "biossegurança e educação".

Dessa forma, não seria necessário restringir a pergunta de partida à metodologia dos cursos nos diferentes níveis de ensino.

Quanto à caracterização dos artigos encontrados no processo de revisão integrativa, os critérios de inclusão definidos para a seleção das publicações foram: (i) publicações em inglês, português, espanhol; (ii) artigos produzidos sobre o ensino biossegurança no Brasil; (iii) artigos completos; (iv) artigos publicados e indexados nos bancos de dados selecionados na pesquisa nos últimos dez anos.

A análise crítica dos estudos selecionados, assim como toda pesquisa, precisa ser organizada. Nessa fase o pesquisador deve observar as evidências encontradas nos estudos selecionados, que podem ser experimentais, descritivos ou qualitativos, assim como as possíveis lacunas do conhecimento.

A etapa de elaboração da revisão necessita ser clara para permitir ao leitor uma avaliação crítica dos resultados encontrados na pesquisa.

\section{RESULTADOS}

Ao realizar buscas nas bases de dados PubMed, SCIELO e BVS utilizando os descritores "Biossegurança e ensino", "Biossegurança e educação", "Contenção de riscos e ensino" e "Contenção de riscos e educação" foram encontrados um total de 58 artigos completos entre os anos de janeiro de 2010 a janeiro de 2020. 
Dos 58 artigos, seis (6) foram identificados na base de dados PubMed, sendo que quatro desses artigos foram identificados com os descritores "Biossegurança e educação" e "Biossegurança e ensino"; um dos artigos foi encontrado apenas ao utilizarmos o descritor "Biossegurança e educação" e um artigo completo foi encontrado ao buscarmos utilizando os descritores "Contenção de riscos e educação" e "Contenção de riscos e ensino" (Figura 1).

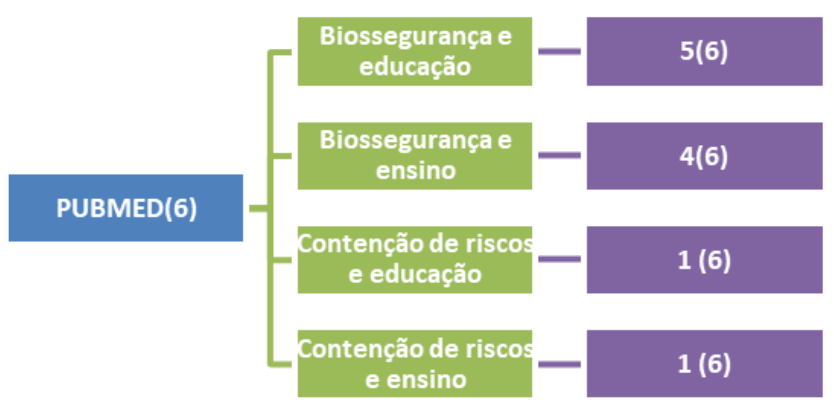

Figura 1. Número de artigos identificados com diferentes combinações de descritores e palavras-chaves na Base de Dados PubMed.

Na Biblioteca Virtual - Scielo, identificamos um total de 27 artigos, sendo 23 identificados com os descritores "Biossegurança e educação", 14 com os descritores "Biossegurança e ensino", dois (2) na busca por "Contenção de riscos e educação" e um (1) para a busca com "Contenção de riscos e ensino". Ao utilizar os quatro (4) descritores na mesma busca apenas um (1) artigo foi identificado. Quando utilizamos tanto os descritores "Biossegurança e ensino" quanto os descritores "Biossegurança e educação", identificamos dez (10) artigos e apenas um (1) artigo ao utilizar os descritores "Contenção de riscos e educação" (Figura 2).

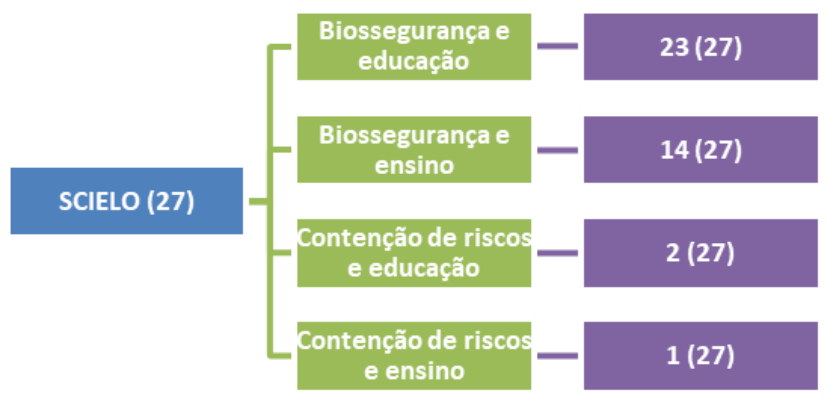

Figura 2. Número de artigos identificados com diferentes combinações de descritores e palavras-chaves na Base de Dados Scielo.

Na Biblioteca Virtual - BVS, identificamos um total de 25 artigos, sendo 21 identificados com os descritores "Biossegurança e educação", 11 com os descritores "Biossegurança e ensino", cinco (5) com os descritores "Contenção de riscos e educação". Apenas dois (2) 
artigos foram identificados a partir dos descritores "Contenção de riscos e ensino", sendo que esses dois (2) artigos também são identificados na busca utilizando qualquer um dos descritores. Além disso, cinco (5) artigos foram identificados quando utilizamos na mesma busca os descritores "Biossegurança e educação" ou "Biossegurança e ensino" (Figura 3).

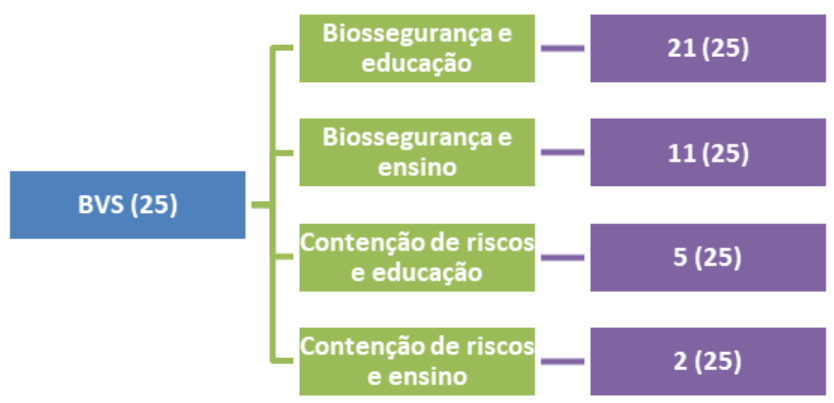

Figura 3. Número de artigos identificados com diferentes combinações de descritores e palavras-chaves na Base de Dados BVS.

As buscas realizadas nas três bases de dados utilizando os descritores "Biossegurança e educação" resultaram em 49 artigos, já através das buscas por meio dos descritores "Contenção de riscos e educação" foram identificados apenas oito (8) artigos. Esses achados diferem também da busca com "Biossegurança e Ensino", duas palavras-chaves, que totalizou em 29 artigos. As buscas utilizando a combinação dos descritores "Contenção de risco e Ensino" também não foram eficientes, pois identificamos apenas quatro (4) artigos.

Após uma triagem constatamos que nove (9) artigos estavam presentes em mais de uma Base de Dados, sendo que três (3) constavam tanto no Scielo como no PubMed, cinco (5) no Scielo e na BVS e um (1) na BVS e PubMed.

Dessa forma, obtivemos um total de 49 artigos durante a etapa de triagem. Porém, após realizarmos a leitura dos trabalhos foi possível notar que, mesmo utilizando descritores que continham as palavras "educação" e "ensino", apenas 33 artigos do total de 49 artigos identificados, apresentavam conteúdo compatível com esse critério. Dessa forma, foram excluidos mais 16 artigos. As publicações identificadas no período de janeiro de 2010 a janeiro de 2020 oscilaram muito em relação ao ano de publicação, apresentando alguns picos de produção na área de biossegurança nos anos de 2010, 2012, 2015, 2018. Ressalta-se que o ano de maior número de artigos nessa área de conhecimento foi em 2012 (8). Nos anos de 2013 e 2020 não houve produção acadêmica na área (Gráfico 1). 


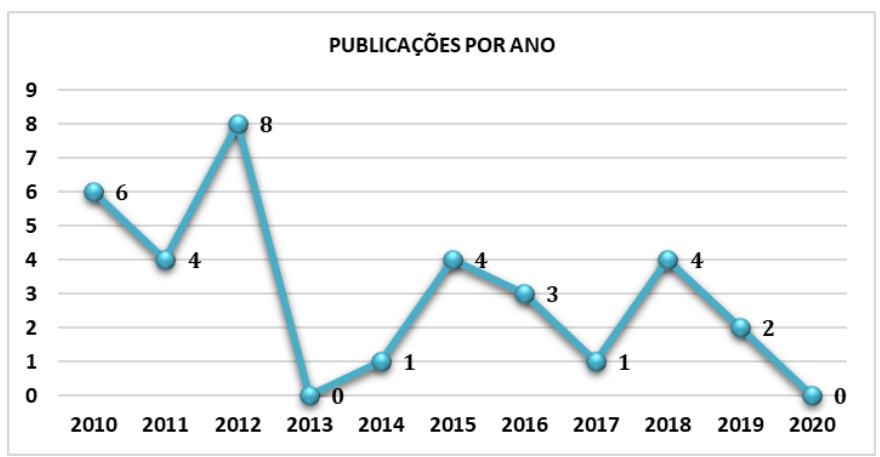

Gráfico 1. Número de artigos publicados por ano sobre Biossegurança e Educação, identificados nas Bases de Dados: PubMed, BVS e Scielo, de 2010 a 22 de janeiro de 2020.

O território brasileiro está dividido em cinco regiões: Norte, Sul, Sudeste, Centro-Oeste e Nordeste, todas com caracteristicas peculiares quanto à natureza física, vegetação, hidrografia, assim como na economia. São nas regiões Sudeste e Sul que estão concentrados os maiores Indices de Desenvolvimento Humano (IDH) do país, também marcadas por grande desigualdade social. Esse fato nos levou a analisar também a origem das publicações identificadas sobre Biossegurança e Ensino. A maioria dessas publicações era oriunda da região Sudeste do Brasil (63,6\%), seguida pelas regiões Sul $(21,2 \%)$ e Nordeste (15,2\%). Não foi identificada nenhuma publicação nas regões Centro-Oeste e Norte. Em relação ao nível de escolaridade ao qual estavam voltados os artigos de Biossegurança no ensino, constatamos que a maioria era para o nivel superior (17) e Educação continuada (6).

Apenas quatro (4) eram direcionados ao ensino técnico; três (3) eram de revisão sobre o tema e três (3) eram de cunho didático, metodologia, avaliação de curso, dentre outros (Gráfico 2).

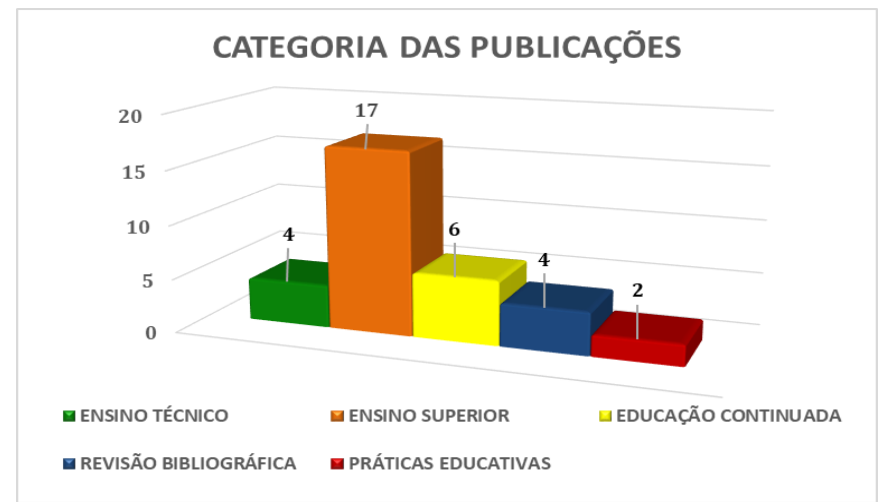

Gráfico 2. Nivel de escolaridade dos sujeitos aos quais estavam direcionadas as publiações identificadas nas diferentes regiões brasileiras e suas respectivas Bases de Dados: PubMed, BVS e Scielo. 


\section{Abaixo listamos as 33 publicações sobre biossegurança e ensino e seus respectivos autores que fizeram parte deste estudo (Tabela 1).}

Tabela 1. Relação dos artigos analisados sobre Biossegurança e Ensino, no períodode 2010 a 21 de janeiro de 2020.

\begin{tabular}{l} 
TíTULO \\
\hline Situação vacinal dos discentes da Faculdade de Medicina da UFJF-MG \\
Biossegurança e Ensino de medicina na Universidade Federal de Juiz de Fora (MG) \\
A estruturação do Programa de Capacitação Profissional de Biossegurança no contexto do \\
Projeto de Modernização da Gestão Científica do Instituto Oswaldo Cruz \\
Construção do conhecimento em biossegurança: uma revisão da produção acadêmica \\
nacional na área de saúde (1989-2009) \\
Educação em biossegurança: contribuições pedagógicas para a formação profissional em \\
saúde \\
Princípios de biossegurança aplicados aos laboratórios de ensino universitário de \\
microbiologia e parasitologia \\
Conhecimento e atitudes de trabalhadores de um serviço público de emergência sobre \\
adoção de precauções padrão \\
Problematização como estratégia para discussão sobre bioética e biossegurança no \\
ensino de zoologia: uma experiência entre licenciandos em ciências biológicas \\
Investigação de acidentes biológicos entre profissionais da equipe multidisciplinar de um \\
hospital \\
Prevenção de acidentes com material biológico entre estudantes de enfermagem \\
The importance of the contextual approach in the teaching of biosafety.- \\
Influenza vaccination among nursing professionals: reality and challenges \\
Biossegurança: comportamento dos alunos de Odontologia em relação ao controle de \\
infecção cruzada \\
A biossegurança e segurança do paciente na visão de acadêmicos de enfermagem \\
O ensino de biossegurança em cursos técnicos em análises clínicas \\
Riscos ocupacionais e medidas de segurança no contexto de prática de estudantes de \\
graduação em enfermagem: uma questão de saúde do trabalhador \\
Avaliação das medidas de biossegurança na formação e atuação dos bombeiros militares
\end{tabular}

A importância de medidas de biossegurança como prevenção de acidentes do trabalho através da identificação de riscos biológicos no mapa de risco.

Percepção de equipes de saúde bucal no norte de Minas Gerais sobre a formação de técnicos em saúde bucal do SUS

Uso de Simuladores para Treinamento de Prevenção de Infecções Relacionadas à Assistência à Saúde

Medidas de biossegurança adotadas por profissionais atuantes em audiologia Concepção de biossegurança de docentes do ensino técnico de enfermagem em um Estado do Sul do Brasil

Biossegurança e gerenciamento de resíduos de serviços de saúde: a importância na formação do profissional da Odontologia na perspectiva da saúde humana e ambiental Avaliação das Práticas de Higienização por Estudantes de Medicina da Universidade Federal da Bahia (Brasil) durante Atendimento Clínico

Dental students' reports of occupational exposures to potentially infectious biological material in a Brazilian School of Dentistry

Práticas de biossegurança no ensino técnico de enfermagem

Redes sociais na aprendizagem em odontologia: opinião dos estudantes de uma universidade brasileira

Implantação de um software para controle da central de esterilização do curso de Odontologia da Universidade Positivo

O OSCE na avaliação clínica odontológica: relato de experiência com estudantes de graduação

Acidentes perfurocortantes envolvendo material biológico: o dizer e o fazer de estudantes de um curso de graduação em Odontologia

Biossegurança: fatores de risco vivenciados pelo enfermeiro no contexto de seu trabalhoREVISÃO

Biossegurança em Odontologia: conduta dos estudantes antes e após uma ação educativa Profile of victims of accidents with biological material in a course of Dentistry

\section{AUTOR/ANO}

CHEHUEN NETO, et

al., 2010

Antunes et al., 2010

PEREIRA et al., 2010

PEREIRA et al., 2010

COSTA \& COSTA,

2010.

SANGIONI et al., 2010

PAIVA \& OLIVEIRA,

2011

LIMA, 2011

CÂMARA, 2011

CANALLI et al., 2011. PEREIRA et al.,2012 VIEIRA et al.,2012 PIMENTEL et al.,2012

CARARRO et al.,2012 PICCOLl et al., 2012 MARTINS et al., 2012

DE OLIVEIRA et al., 2012

DE CASTRO

METELLO et al., 2012

SILVA et al., 2014

SILVA et al., 2015

ROCHA et al., 2015

RIBEIRO et al., 2015

LEAL, 2015.

SANTANA-CAIRES et al. ,2016

PINELLI et al., 2016.

RIBEIRO et al., 2016

SOUZA et al., 2017

SILVA et al., 2018

DE ALMEIDA et al., 2018

MAZUTTI et al., 2018

ANDRADE et al., 2018

LOPES et al., 2019

TSUZUKI et al., 2019 


\section{DISCUSSÃO}

Nas buscas realizadas nesta pesquisa utilizamos uma combinação de palavras-chave e seus respectivos descritores em Ciências da Saúde, segundo a Biblioteca Virtual de Saúde. Nas buscas com a combinação "biossegurança e educação", ou seja, uma palavra-chave e um descritor respectivamente, foram identificados seis vezes mais publicações do que quando utilizamos os dois descritores "contenção de riscos e educação". A escolha por essa técnica de busca foi no intuito de identificar o maior número de artigos possível dentro da temática proposta, não restringindo a nossa pergunta de partida à metodologia de cursos. Além disso, há algumas discussões quanto à utilização de descritores e palavraschave, em relação às buscas nas bases de dados. Os descritores podem atuar como filtros, tornando a busca mais específica (Pompei, 2010), logo diminuem o número da amostra. Ademais, há o risco de não se detectar determinadas publicações que foram inseridas inadequadamente pelos autores (Timi, 2005). A utilização de palavras-chave podem ampliar as buscas, ou dimerir a perda, porque as bases de dados de alta qualidade conseguem agrupar palavras não padronizadas a descritores padronizados, como ocorreu na nossa busca (Pompei, 2010). Entretanto, constatamos a importância da utilização dos descritores, pois um dos artigos apenas foi detectado utilizando os dois descritores, ou seja, "Contenção de riscos e educação". Contudo, a forma em que identificamos o maior número de artigos (22) foi utilizando nas buscas a palavra-chave "Biossegurança" e o descritor "Educação".

A grande quantidade de artigos no período de 2010 a 2012 pode estar relacionada ao fato de o termo "Biossegurança" estar na "mídia" devido a fatores legislativos, como citado por Costa e Costa (2010). O assunto estava circulando na mídia porque, em 2010, o Ministério da Saúde, por meio da Portaria №3.204, aprovou a Norma Técnica de Biossegurança para Laboratórios de Saúde Pública que objetivava especificar requisitos gerais para atividades laborais a fim de reduzir e/ou eliminar fatores de risco associados a esse tipo de ambiente (Brasil, 2010). Provavelmente esses sucessivos acontecimentos tenham influenciado os acadêmicos a desenvolverem pesquisas referentes à biossegurança, o que refletiu no aumento de publicações entre os anos de 2010 e 2012. Em relação à educação, verificamos nos artigos identificados que no campo de biossegurança a educação continuada se mostra um caminho promissor, assim como a utilização de práticas de ensino baseadas na teoria construtivista (Piccoli, 2012). Entretanto, o campo da educação, ou ensino e/ou práticas educativas em biossegurança, ainda não é bem desenvolvido, pois a mesma escassez de publicações identificada nesse estudo, também foi relatada por Pereira e colaboradores (2010) em uma revisão sistemática. Esses autores também identificaram a região Sudeste 
como a maior produtora de publicações nessa área. Assim como esses autores acreditamos que esse fato esteja relacionado à grande concentração de grupos de pesquisa localizado nessa região, onde se concentra um grande número de universidades e instituições de pesquisas. A partir da análise realizada neste trabalho foi possivel notar que, entre os anos de 2010 e 2020, os resultados permanecem bastante similares aos apresentados 20 anos antes.

De acordo com o censo da educação superior realizado em 2018 pelo Instituto Nacional de Ensino e Pesquisa (INEP), existem 2.537 instituições de graduação e pós-graduação no Brasil. As instituições particulares são maioria, sendo esse total de 2.238 (Brasil, 2018). A quantidade de estudantes de ensino superior pertencentes à região sudeste chega a 46\% do total de estudantes de todo o território brasileiro, enquanto as regiãos Norte $(8,2 \%)$ e Centro-oeste (10\%) ocupam as últimas posições do ranking. As regiões Sul $(17 \%)$ e Nordeste $(19,3 \%)$ apresentam um total bastante próximo de estudantes que frequentam o ensino superior (Brasil, 2018). Outro fator que pode exercer influência sobre a quantidade de publicações apresentadas em cada região brasileira é o fator orçamentário. De acordo com a revisão orçamentária para a educação realizada pela Câmara dos Deputados referente ao ano de 2018, as Universidades Federais do Rio de Janeiro, de Minas Gerais e do Rio Grande do Sul possuem os maiores orçamentos do Brasil (Brasil, 2019). Ao receber mais investimentos financeiros as instituições conseguem financiar pesquisas e, consequentemente, gerar maior número de publicações. Nos artigos identificados evidenciamos que o ensino de biossegurança está, em sua maioria, voltado para o ensino superior. De 2010 a 2020, o curso de Odontologia foi o maior contemplado, seguido dos cursos de Enfermagem e Medicina. Entretanto, um estudo realizado em universidades localizadas na cidade do Rio de Janeiro demonstrou que estudantes do último ano de Odontologia são incapazes de realizar as condutas básicas de biossegurança (Medeiros, Cardoso, \& Ferreira, 1998). Entre recém formados e formados há mais de 10 anos ainda são encontradas falhas preocupantes relacionadas a procedimentos em Biossegurança (Abreu et al., 2009). Entre os seis (6) artigos sobre educação continuada, nenhum deles realiza menção aos profissionais da área odontológica. É possivel que esse déficit no cumprimento das normas de biossegurança esteja interligado à necessidade de mais programas e metodologias que estimulem a sensibilização de profissionais já graduados. Ao analisarmos as matrizes curriculares de Odontologia das três principais universidades públicas da região Sudeste, foi evidenciado que as Universidades Federais do Rio de Janeiro (UFRJ) e de Minas Gerais (UFMG) não apresentam nenhuma disciplina que aborde 
em seu título o ensino de Biossegurança. Já a Universidade de São Paulo (USP) apresenta em sua matriz curricular a disciplina de Biossegurança I e II, ofertada no $2^{\circ}$ e $3^{\circ}$ períodos, respectivamente. Apesar da importância da Biossegurança no cotidiano do profissional da área da saúde, Costa e Costa (2010) afirmaram que é recente a incorporação de biossegurança nas matrizes curriculares de ensino superior. Entretanto, pela quantidade de publicações sobre biossegurança existente na área de Odontologia, os autores acreditam que a temática Biossegurança está incorporada nos cursos de Odontologia há bastante tempo. Como as matrizes curriculares consultadas evidenciam essa questão, a temática pode estar inserida nas disciplinas de forma fragmentada.

Durante a análise dos artigos também verificamos que nos anos iniciais do ensino superior existem falhas no ensino de Biossegurança no que se refere à vacinação e equipamentos de proteção individual (EPI). Alguns estudantes de medicina não eram vacinados contra doenças básicas como hepatite $B$, desconheciam as precações universais e não utilizavam Equipamento de Proteção Individual (EPI).

Os estudantes declararam que receberam informações sobre esses itens em diferentes disciplinas e que em suas atividades acadêmicas entraram em contato com materiais potencialmente contaminados e/ou relataram acidentes de trabalho (Chehuen Neto et al., 2010; Antunes et al., 2010).

Esses resultados demonstram que o ensino de Biossegurança está ocorrendo de forma compartimentalizada e fragmentada (Costa \& Costa, 2010). Além disso, a inserção de futuros profissionais de saúde em uma universidade de medicina sem a atualização do cartão de vacinas vai de encontro às obrigações instituídas por lei. Desde oito de abril de 2004 foi instituida no Brasil a Portaria de $n^{\circ}$ 597/GM, no intuito de estabelecer normas sobre o Programa Nacional de Imunizações. O parágrafo 2 do Art $5^{\circ}$ versa sobre a obrigatoriedade do cartão de vacinação atualizado para a realização de matrícula na educação básica e universidade, com um prazo máximo para a atualização de 60 dias (Brasil, 2004).

Em relação ao ensino técnico, foi possível identificar seis (6) artigos, sendo dois (2) voltados para técnicos em enfermagem, um (1) para técnicos em saúde bucal, um (1) para análises clínicas e dois (2) que foram classificados como artigos de "Práticas educativas". O ensino técnico apresenta uma quantidade inferior de publicações. Isso pode estar relacionado ao fato de que, apesar de importante, a Biossegurança começou a ser incorporada aos cursos técnicos recentemente (Costa \& Costa, 2010). Entre esses, dois (2) trabalhos (Piccoli et al., 
2012; Ribeiro et al., 2016) são provenientes da Escola Politécnica de Saúde Joaquim Venâncio (EPSJV) localizada na Fundação Oswaldo Cruz no Rio de Janeiro. A EPSJV possui um grupo de Pesquisa e Estudos em Biossegurança voltada para a educação de profissionais em técnicas laboratoriais de saúde e por esse motivo apresenta maior número de publicações nos últimos anos no ensino técnico em Biossegurança (Costa \& Costa, 2010). Os artigos relacionados como "Práticas educativas" também são provenientes dessa instituição (Costa e Costa, 2010; Pereira et al., 2012).

Para Pereira e colaboradores (2012) os conceitos estruturantes "perigo" e "acidente", apresentados por Costa e Costa (2010), são complementares ao conceito "risco".

Os autores entendem que o conceito de "risco" é capaz de modificar significados no sistema cognitivo do estudante. O conceito "perigo" é interpretado como a causa desse risco e "acidente" é a concretização do risco. Pereira et al. (2012) e Costa e Costa (2010) também alertam para a contextualização no ensino de Biossegurança. Para os autores é necessário desconstruir a visão de que a ciência é um produto simples e acabado, a fim de alcançar um processo ensino e aprendizagem significativos.

O contexto histórico, social e cultural deve ser considerado para que o estudante ocupe uma posição ativa e consiga realmente interferir na sua realidade, seja ela qual for. Entretanto, em pesquisa realizada por Costa e Costa (2010) em seis (6) cursos técnicos de Biossegurança da Fiocruz/RJ, ficou constatado que a maioria dos docentes entrevistados utiliza metodologias tradicionais. Por outro lado, a maioria dos discentes afirmou não participar das aulas, nem ao menos para questionar.

Os autores atribuem essa postura dos discentes à postura dos docentes tradicionais. É possível que o ensino tradicional de Biossegurança desestimule o interesse dos estudantes. Os autores identificaram também a importância de se associar teoria e prática no ensino de Biossegurança, pois profissionais de saúde que atuam na área conseguem fazer mais conexões e apreensão de informações.

De acordo com os autores, as práticas coletivas e investigativas são mais indicadas para o ensino de Biossegurança porque os estudantes se sentem mais preparados e ativos enquanto futuros profissionais da saúde. 


\section{CONCLUSÃO}

Os cortes recentes e as diferenças de investimentos em determinadas regiões do Brasil podem influenciar no número de publicações em Biossegurança. Apesar de ser notória a importância do tema para docentes, profissionais e estudantes da área da saúde, as metodologias utilizadas em diferentes níveis de ensino não têm se mostrado eficientes. $O$ ensino fragmentado e descontextualizado de Biossegurança pode ser um dos fatores determinantes para o alto índice de acidentes entre os profissionais de saúde no ambiente de trabalho. Práticas coletivas e investigativas são alternativas viáveis ao ensino tradicional que apenas desestimula os estudantes e forma profissionais inseguros e despreparados. É importante ressaltar que a educação continuada é um meio efetivo de minimizar riscos e aguçar o olhar de profissionais para práticas cotidianas aparentemente inofensivas. Entretanto, são necessários mais estudos que abordem metodologias e práticas bemsucedidas, a fim de desenvolver um processo ensino e aprendizagem efetivos, contextualizados e significativos.

\section{REFERÊNCIAS}

Abreu, M. H. et al. (2009). Attitudes and behavior of dental students concerning infection control rules: a study with a10-year interval. Brazilian dental journal, 20(3), 221-225.

Antunes, H. M. et al. (2010). Biossegurança e ensino de medicina na Universidade Federal de Juiz de Fora,(MG). Revista Brasileira de Educação Médica, 34(3), 335-345.

Brandau, R., Monteiro, R., \& Braile, D. M. (2005). Importância do uso correto dos descritores nos artigos científicos. Brazilian Journal of Cardiovascular Surgery, 20(1), VII-IX.

Brasil. Ministério da Saúde (2004). Portaria no 597/GM de 8 de abril de 2004. Institui em todo o território nacional os calendários de vacinação. Dou. Brasília: MS.

Brasil (2010). Ministério da Saúde. Portaria no 3.204, de 20 de outubro de 2010. Aprova Norma Técnica de Biossegurança para Laboratórios de Saúde Pública. Brasília: Ministério da Saúde.

Brasil (2018). Instituto Nacional de Estudos e Pesquisas Educacionais Anísio Teixeira (Inep). Censo da Educação Superior 2018-Divulgação dos Resultados. Disponível em: http://download.inep.gov.br/educacao_superior/censo_superior/documentos/2019/apresentacao_censo _superior2018.pdf. Acesso em: 27 fev. 2020.

Brasil (2019). Câmara dos Deputados. Consultoria de Orçamento e Fiscalização Financeira. Revisão Orçamentária 2019: diagnóstico para educação: possibilidades e perspectivas, Brasília, DF, 2019. Disponível em: <https://www2.camara.leg.br/orcamento-dauniao/estudos/2018/Revisooramentria2019_Educao_diagnstico.pdf>. Acesso em: 01 mar. 2020.

Chehuen Neto, J. A. et al. (2010). Situação vacinal dos discentes da Faculdade de Medicina da UFJFMG. Revista Brasileira de Educação Médica, 34(2), 270-277.

Costa, M. A., \& Costa, M. F. (2010). Educação em biossegurança: contribuições pedagógicas para a formação profissional em saúde. Ciência \& Saúde Coletiva, 15, 1741-1750. 
Costa, M. A. (1996). Biossegurança: segurança química básica em biotecnologia e ambientes hospitalares. Livraria Santos.

Medeiros, U. V., Cardoso, A. S., \& Ferreira, S. M. (1998). Uso das normas de controle de infecçäo na prática odontológica. Rev. bras. odontol, 209-15.

Mendes, K. Dal S., Silveira, R. C., \& Galvão, C. M. (2008). Revisão integrativa: método de pesquisa para a incorporação de evidências na saúde e na enfermagem. Texto \& Contexto-Enfermagem, 17(4), 758-764.

Minayo, M. C. (2002). Pesquisa social: teoria e método. Ciência, Técnica.

Penna, P. M. M. et al. (2010). Biossegurança: uma revisão. Arquivos do Instituto Biológico, 77(3), 555-465.

Pereira, M. E. et al. (2010). A estruturação do Programa de Capacitação Profissional de Biossegurança no contexto do projeto de modernização da gestão científica do Instituto Oswaldo Cruz. Saúde e Sociedade, $v$. 19(2), 440-448.

Pereira, M. E. et al. (2012). The importance of the contextual approach in the teaching of biosafety. Ciencia \& saude coletiva, 17(6), 16-43.

Piccoli, A., Wermelinger, M., \& Amâncio Filho, A. (2012). O ensino de biossegurança em cursos técnicos em análises clínicas. Trabalho, Educação e Saúde, v. 10(2), 283-300.

Pompei, L. (2010). Descritores ou palavras-chave nas bases de dados de artigos científicos. Femina, 38(5), 232.

Ribeiro, G., Pires, D. E., \& Scherer, M. D. (2016). Práticas de biossegurança no ensino técnico de enfermagem. Trabalho, Educação e Saúde, 14(3), 871-888.

Scholze, S. (1999). Biossegurança e alimentos transgênicos. Biotecnologia Ciência e Desenvolvimento, 9(2), 3234.

Shatzmayr, H. G. (2001). Biossegurança nas infecções de origem viral. Revista Biotecnologia, Ciência e Desenvolvimento, 3(18), 12-15.

Souza, M. T., Silva, M. D., \& Carvalho, R. (2010). Revisão integrativa: o que é e como fazer. Einstein, 8(1), 102106.

Timi, J. R. (2005). A importância do uso dos descritores nas publicações médicas. Jornal Vascular Brasileiro, $4(2), 114-115$. 